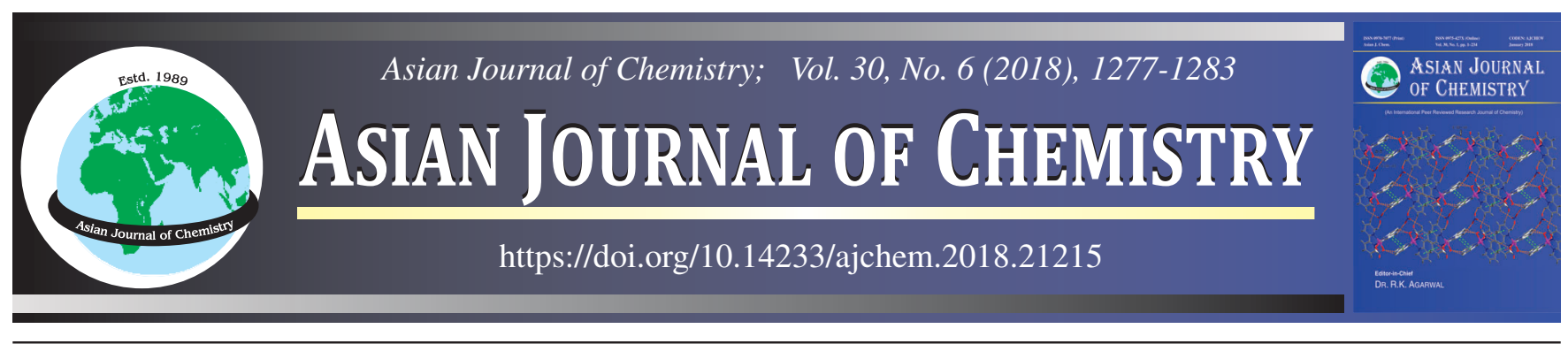

\title{
Stability-Indicating RP-HPLC Method for Simultaneous Quantification of Ombitasvir, Paritaprevir and Ritonavir in Tablet Dosage Form
}

\author{
Mangamma Kuna ${ }^{1,2, *}$ and Gowri Sankar Dannana ${ }^{2}$
}

${ }^{1}$ School of Pharmacy, Jawaharlal Nehru Technological University-Kakinada, Kakinada-533003, India

${ }^{2}$ Department of Pharmaceutical Analysis and Quality Assurance, University College of Pharmaceutical Sciences, Andhra University, Visakhapatnam530003 , India

*Corresponding author: E-mail: kunamanga@gmail.com

Received: 8 January 2018;

Accepted: 9 February 2018;

Published online: 30 April 2018;

AJC-18880

| A new stability indicating RP-HPLC method has been developed for simultaneous estimation of ombitasvir, paritaprevir and ritonavir in bulk and tablet dosage form. The method involves separation and analysis of the selected drugs on Inertsil ODS C18 $(4.6 \mathrm{~mm} \times 250 \mathrm{~mm}$, $5 \mu \mathrm{m})$. The optimized mobile phase consists of orthophosphoric acid $(40 \%)$ : acetonitrile $(60 \%)$ with a flow rate of $1 \mathrm{~mL} / \mathrm{min}$ and detection at $252 \mathrm{~nm}$. Retention time was $2.056 \mathrm{~min}$ for ombitasvir, $2.821 \mathrm{~min}$ for paritaprevir and 4.853 min for ritonavir. The developed method was validated as per the ICH guidelines. Linearity was observed in the range of $6.25-31.25 \mu \mathrm{g} / \mathrm{mL}$ for ombitasvir, 37.5-187.5 $\mu \mathrm{g} / \mathrm{mL}$ for paritaprevir and $25-125 \mu \mathrm{g} / \mathrm{mL}$ for ritonavir with good correlation coefficient value $(>0.9990)$. The percentage recoveries of ombitasvir, paritaprevir and ritonavir were in the range of $99.98-100.69 \%, 99.16-100.75 \%$ and $99.82-100.08 \%$, respectively. The percentage relative standard deviation was $<2 \%$. The method had the ability to quantify the drugs simultaneously from tablets dosage forms with no interference from the tablets excipients. Ombitasvir, paritaprevir and ritonavir were also subjected to acid, base, oxidation and thermal degradation studies. The proposed method effectively analyzed the studied drugs in the presence of their degradation products.

Keywords: Ombitasvir, Paritaprevir, Ritonavir, Stability indicating, HPLC, Analysis.

\section{INTRODUCTION}

Ombitasvir, chemically known as methyl N-[(2S)-1-[(2S)2-[[4-[(2S,5S)-1-(4-tert-butylphenyl)-5-[4-[[(2S)-1-[(2S)-2(methoxycarbonylamino)-3-methylbutanoyl]pyrrolidine-2carbonyl]amino]phenyl]pyrrolidin-2-yl]phenyl]carbamoyl]pyrrolidin-1-yl]-3-methyl-1-oxobutan-2-yl]carbamate, is an anti viral agent used in combination therapy in the treatment of chronic hepatitis $\mathrm{C}$ infection [1]. Ombitasvir block the viral RNA replication by blocking the activity of NS (non-structural) $5 \mathrm{~A}$ protein which plays a vital role in hepatitis $\mathrm{C}$ virus RNA replication [2].

Paritaprevir, chemically described as $(2 \mathrm{R}, 6 \mathrm{~S}, 12 \mathrm{Z}, 13 \mathrm{aR}$, $14 \mathrm{aR}, 16 \mathrm{aS})-\mathrm{N}$-(cyclopropanesulfonyl)-6-[(5-methylpyrazine2-carbonyl)amino]-5,16-dioxo-2-[(phenanthridin-6-yl)oxy]$1,2,3,6,7,8,9,10,11,13 \mathrm{a}, 14,15,16,16 \mathrm{a}-\mathrm{tetradecahydrocyclo-}$ propa[e]pyrrolo[1,2-a][1,4]diazacyclopentadecine-14a (5H)carboxamide is an synthetic acylsulfonamide antiviral agent used in combination therapy in the treatment of chronic hepatitis C infection [3,4]. Paritaprevir acts as an inhibitor of non-structural protein 3 and 4A (NS3/NS4A) complex. The inhibition of this complex interrupts the processing of viral proteins and development of viral replication complex, which inturn inhibits viral replication.

Ritonavir, chemically known as 1,3-thiazol-5-ylmethyl N[(2S,3S,5S)-3-hydroxy-5-[[(2S)-3-methyl-2-[[methyl-[(2propan-2-yl-1,3-thiazol-4-yl)methyl]carbamoyl]amino]butanoyl]amino]-1,6-diphenylhexan-2-yl]carbamate, is an peptidomimetic agent that block the activities of HIV-1 and HIV-2 proteases and also acts an inhibitor for Cytochrome $\mathrm{P} 450$ 3A. Ritonavir is not an antiviral agent for hepatitis $\mathrm{C}$ virus infection. But it is used in combination therapies for the treatment of hepatitis $C$ virus infection as a booster $[5,6]$. Through inhibiting Cytochrome P450 3A, ritonavir increases plasma concentration of other protease inhibitors like paritaprevir.

A fixed dose combination of ombitasvir, paritaprevir and ritonavir is approved by FDA in 2015 for the management of chronic hepatitis $\mathrm{C}$ virus genotype 4 infection with no cirrhosis $[7,8]$. The combination of studied drugs is not listed in any pharmacopoeia. Literature survey revealed that there are only two number of HPLC methods for the quantification of selected drug combination $[9,10]$. An RP-HPLC method for the determination of ombitasvir, paritaprevir and ritonavir in bulk and its dosage forms was presented by Srinivas and Yadagiriswamy 
[9]. They used Inertsil ODS C-18 analytical column and $0.1 \%$ orthophosphoric-acetonitrile (40:60 v/v, $\mathrm{pH} 3$ ) as mobile phase with UV detection at $252 \mathrm{~nm}$. The retention times for ombitasvir, paritaprevir and ritonavir were $2.315 \mathrm{~min}, 2.89 \mathrm{~min}$ and 5.483 min, respectively. Phani et al. [10] determined ombitasvir, paritaprevir and ritonavir in spiked human plasma by HPLC with UV detection at $230 \mathrm{~nm}$ using an Intersil ODS C18 analytical column and a mobile phase consisting of acetonitrile, methanol, $1 \mathrm{mM} \mathrm{NH} \mathrm{H}_{2} \mathrm{PO}_{4}$ buffer (20:20:60 v/v/v, pH 6.5). The retention times of ritonavir, ombitasvir and paritaprevir are $5.7 \mathrm{~min}, 7.8 \mathrm{~min}$ and $12.8 \mathrm{~min}$, respectively.

However, no method is reported for simultaneous estimation of these three drugs, ombitasvir, paritaprevir and ritonavir, by stability indicating RP-HPLC method. The aim of the present study is to develop and validate a new stability indicating RP-HPLC method for simultaneous quantification of ombitasvir, paritaprevir and ritonavir in bulk and in its tablet dosage form.

\section{EXPERIMENTAL}

HPLC grade acetonitrile, analytical grade hydrochloric acid, sodium hydroxide and hydrogen peroxide were from Ramkem (Haryana, India). Milli-Q-water was used throughout the process. Analytical grade orthophosphoric acid was purchased from Fischer Scientific, Mumbai, India.

Reference drugs and pharmaceutical dosage form: The working standards paritaprevir and ritonavir generous gift samples from Manus Aktteva Biopharma LLP (Ahmedabad, India) and ombitasvir was generous gift obtained from Laurus Labs (Hyderabad, India). Technivie ${ }^{\mathrm{TM}}$ tablets (AbbVie Inc. Chicago) labeled to contain ombitasvir $12.5 \mathrm{mg}$, paritaprevir $75 \mathrm{mg}$ and ritonavir $50 \mathrm{mg}$ was obtained from the local pharmacy store.

Separation and analysis of selected drug combination was performed on Waters 2695 separation module equipped with a waters 1525 binary HPLC pump, a Waters 2998 photodiode array detector and a Waters 2707 autosampler. The data were acquired and processed using Windows Empower-2 software.

Chromatographic conditions: The chromatographic separations were carried out on a reverse phase Inertsil ODS C18 column $(250 \mathrm{~mm} \times 4.6 \mathrm{~mm}, 5 \mu \mathrm{m})$. The mobile phase used was a mixture of acetonitrile and $0.1 \%$ orthophosphoric acid (60:40, v/v; $\mathrm{pH}$ adjusted to 3.0 with diluted $\mathrm{NaOH}$ ) delivered at a flow rate of $1 \mathrm{~mL} / \mathrm{min}$. The mobile phase was filtered via $0.45 \mu \mathrm{m}$ Whatman filter paper and sonicated for $20 \mathrm{~min}$. Analysis was performed at ambient temperature and the elution of the compounds was monitored by diode array detector. The chromatograms were recorded at $252 \mathrm{~nm}$ and the injection volume was $10 \mu \mathrm{L}$.

Standard solutions: Stock standard solution was made by dissolving $25 \mathrm{mg}$ of ombitasvir, $150 \mathrm{mg}$ of paritaprevir and $100 \mathrm{mg}$ of ritonavir in $100 \mathrm{~mL}$ of mobile phase in a clean dry $100 \mathrm{~mL}$ volumetric flask. The contents of the flask were sonicated to dissolve drugs completely. For linearity testing, working standard solutions containing $6.25,12.5,18.75,25.0$ and 31.25 $\mu \mathrm{g} / \mathrm{mL}$ of ombitasvir, 37.5, 75, 112.5, 150 and $187.5 \mu \mathrm{g} / \mathrm{mL}$ of paritaprevir and 25, 50,75, 100 and $125 \mu \mathrm{g} / \mathrm{mL}$ of ritonavir were prepared by apt dilution of the stock standard solution with mobile phase. For studying the remaining validation parameters, a working standard solution containing $25 \mu \mathrm{g} / \mathrm{mL}$, $150 \mu \mathrm{g} / \mathrm{mL}$ and $100 \mu \mathrm{g} / \mathrm{mL}$ of ombitasvir, paritaprevir and ritonavir, respectively was prepared from stock solution through proper dilution with mobile phase.

Tablet sample solution: Average weight of 10 tablets were calculated. The tablets were crushed into powder using a mortar and pestle. Powder equivalent to $25 \mathrm{mg}$ of ombitasvir, $150 \mathrm{mg}$ of paritaprevir and $100 \mathrm{mg}$ of ritonavir was transferred into a $100 \mathrm{~mL}$ clean dry volumetric flask. Added about $70 \mathrm{~mL}$ of mobile phase to the flask and sonicated up to $30 \mathrm{~min}$ to dissolve them completely. Then make up the volume to the mark with the same solvent. The resultant solution was filtered through 0.45 micron Injection filter. For analysis, $1 \mathrm{~mL}$ from the above prepared tablet sample solution was diluted to $10 \mathrm{~mL}$ with mobile phase in a $10 \mathrm{~mL}$ volumetric flask. The resultant solution has a concentration $25 \mu \mathrm{g} / \mathrm{mL}$ of ombitasvir, $150 \mu \mathrm{g} / \mathrm{mL}$ of paritaprevir and $100 \mu \mathrm{g} / \mathrm{mL}$ of ritonavir.

Calibration curve: Standard calibration curves were prepared with the injection of working standard solutions at five concentration levels (ombitasvir - 6.25, 12.5, 18.75, 25.0 and $31.25 \mu \mathrm{g} / \mathrm{mL}$; paritaprevir - 37.5, 75, 112.5, 150 and 187.5 $\mu \mathrm{g} / \mathrm{mL}$; ritonavir $-25,50,75,100$ and $125 \mu \mathrm{g} / \mathrm{mL}$ ). The peak area response at each concentration level for all the drugs were determined using described chromatographic conditions. The least squares regression analyses of the peak area to concentration ratio were calculated. The concentration of the unknown can be determined either using the corresponding calibration curve or regression equation.

Assay of selected drugs in tablet dosage form: $10 \mu \mathrm{L}$ of the tablet sample solution prepared was injected into the chromatographic system. The peak area responses for ombitasvir, paritaprevir and ritonavir were measured. The percentage assay of ombitasvir, paritaprevir and ritonavir was determined either using the corresponding calibration curve or regression equation.

Stress degradation studies: Stress degradation studies were performed, according to International Conference on Harmonization guidelines [11], on the ombitasvir, paritaprevir and ritonavir tablet sample solution to elucidate the inherent stability characteristics of the active substance and also to assess the specificity of the proposed method.

Hydrolytic degradation under acidic condition: $1 \mathrm{~mL}$ of tablet sample solution (ombitasvir - $250 \mu \mathrm{g} / \mathrm{mL}$, paritaprevir - $1500 \mu \mathrm{g} / \mathrm{mL}$ and ritonavir - $1000 \mu \mathrm{g} / \mathrm{mL}$ ) was transferred into a $10 \mathrm{~mL}$ clean dry volumetric flask. $3 \mathrm{~mL}$ of $1 \mathrm{~N} \mathrm{HCl}$ was added. Then, the volumetric flask was kept at $60^{\circ} \mathrm{C}$ for $6 \mathrm{~h}$ followed by neutralization with sufficient volume of $1 \mathrm{~N} \mathrm{NaOH}$. The volume of the flask was made up to $10 \mathrm{~mL}$ with mobile phase. Filtered the solution with 0.22 microns syringe filters and placed in vials for injection into the HPLC system.

Hydrolytic degradation under alkaline condition: $1 \mathrm{~mL}$ of tablet sample solution (ombitasvir - $250 \mu \mathrm{g} / \mathrm{mL}$, paritaprevir - $1500 \mu \mathrm{g} / \mathrm{mL}$ and ritonavir - $1000 \mu \mathrm{g} / \mathrm{mL}$ ) was transferred into a $10 \mathrm{~mL}$ volumetric flask and added $3 \mathrm{~mL}$ of $1 \mathrm{~N} \mathrm{NaOH}$. The flask was kept at $60{ }^{\circ} \mathrm{C}$ for $6 \mathrm{~h}$, neutralized with adequate volume of $1 \mathrm{~N} \mathrm{HCl}$ and then made up to $10 \mathrm{~mL}$ with mobile phase. The resultant solution was filtered with $0.22 \mu$ syringe filters and placed in vials for injection into the HPLC system. 
Thermal induced degradation: Tablet sample powder equivalent to $25 \mathrm{mg}$ of ombitasvir, $150 \mathrm{mg}$ of paritaprevir and $100 \mathrm{mg}$ of ritonavir was taken in petri dish and kept in hot air oven at $110{ }^{\circ} \mathrm{C}$ for $24 \mathrm{~h}$. After the specified period of degradation, the sample was cooled and the solution was prepared as described in section "Tablet sample solution". The prepared sample was injected into HPLC system and analyzed.

Oxidative degradation: $1 \mathrm{~mL}$ of tablet sample solution (ombitasvir - $250 \mu \mathrm{g} / \mathrm{mL}$, paritaprevir - $1500 \mu \mathrm{g} / \mathrm{mL}$ and ritonavir - $1000 \mu \mathrm{g} / \mathrm{mL}$ ) was transferred into a $10 \mathrm{~mL}$ volumetric flask. To the same flask $1 \mathrm{~mL}$ of $30 \%$ hydrogen peroxide was added and kept at room temperature for $15 \mathrm{~min}$ after $15 \mathrm{~min}$ the solution was made up to the mark with mobile phase. Filtered the solution with 0.45 microns syringe filters and place in vials for injection into the HPLC system.

UV degradation: Tablet sample powder equivalent to 25 $\mathrm{mg}$ of ombitasvir, $150 \mathrm{mg}$ of paritaprevir and $100 \mathrm{mg}$ of ritonavir was taken in petri dish and kept in UV Chamber for $1 \mathrm{~h}$ or $200 \mathrm{Watt} \mathrm{h} / \mathrm{m}^{2}$ in photo stability chamber. After the specified time period the sample was cooled and the solution was prepared as described in section "Tablet sample solution". The prepared sample was injected into HPLC system and analyzed.

Neutral degradation: $1 \mathrm{~mL}$ of tablet sample solution (ombitasvir - $250 \mu \mathrm{g} / \mathrm{mL}$, paritaprevir - $1500 \mu \mathrm{g} / \mathrm{mL}$ and ritonavir - $1000 \mu \mathrm{g} / \mathrm{mL}$ ) and $1 \mathrm{~mL}$ of water were added in $100 \mathrm{~mL}$ volumetric flask. The flask was kept at $60{ }^{\circ} \mathrm{C}$ reflux condition for $1 \mathrm{~h}$. Cool the solution to room temperature and dilute to $10 \mathrm{~mL}$ with mobile phase. The solution was filtered with 0.22 microns syringe filters and placed in vials for injection into the HPLC system.

\section{RESULTS AND DISCUSSION}

Optimization of HPLC conditions: In this study, we made an attempt to develop and validate a simple, fast and reliable stability indicting RP-HPLC method for the simultaneous determination of ombitasvir, paritaprevir and ritonavir in the presence of their stress degradation products. Various columns like Hypersil, Lichrosorb, Thermosil and Inertsil ODS were tried during method optimization. Among the different columns tried, Inertsil ODS C18 column $(250 \mathrm{~mm} \times 4.6 \mathrm{~mm}$, $5 \mu \mathrm{m})$ was found to be ideal as it gave good peak shape and resolution. Different mobile phase combinations, methanol with orthophosphoric acid and methanol with phosphate buffer, with varying proportions, different $\mathrm{pH}$ and flow rate were tried. Finally, the mobile phase was optimized was $0.1 \%$ orthophosphoric acid (pH 3.0) and acetonitrile in the proportion of 40:60 $(\mathrm{v} / \mathrm{v})$ at a flow rate of $1 \mathrm{~mL} / \mathrm{min}$ was selected as it gave good results. UV spectrum of ombitasvir, paritaprevir and ritonavir in mobile phase composition was recorded by scanning in the range of 200 to $400 \mathrm{~nm}$. From the results $252 \mathrm{~nm}$ was selected as analytical wavelength. At this wavelength all these three drugs show good absorbance. Using the optimized chromatographic conditions, ombitasvir, paritaprevir and ritonavir are eluted from the column with retention times $2.056 \mathrm{~min}, 2.821$ min and $4.853 \mathrm{~min}$, respectively (Fig. 1).

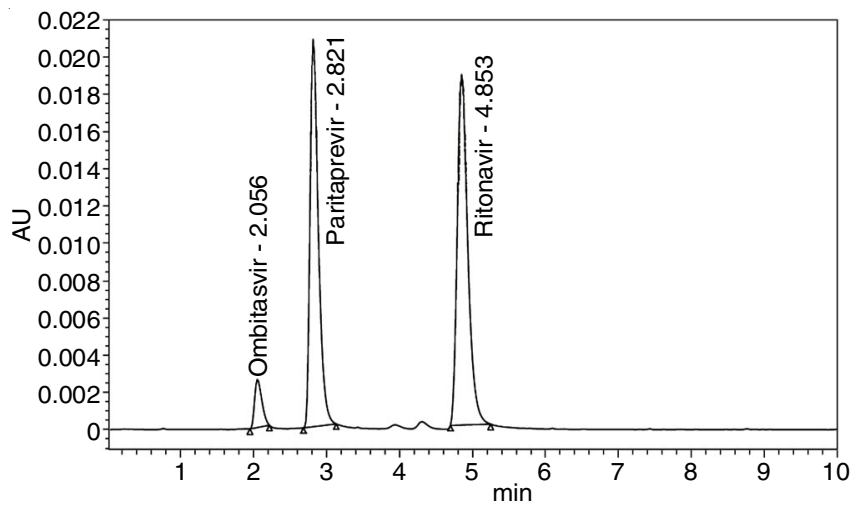

Fig. 1. Chromatogram for ombitasvir, paritaprevir and ritonavir after method optimization

Method validation: The developed method was validated according to the described procedures in International Conference on Harmonization guidelines [12] covering system suitability, selectivity, specificity, linearity, precision, accuracy, robustness, ruggedness, detection limit and quantification limit.

System suitability: To evaluate the system suitability, parameters like tailing factor, theoretical plates and percent relative standard deviation for peak area and retention were determined six replicate injections. The results are found to be within the limits and were presented in Table-1.

Selectivity: To establish the selectivity of the method, tablet sample solution, standard drug solution, placebo blank solution and mobile phase blank were analyzed to verify the absence of interfering substances around the retention time of ombitasvir, paritaprevir and ritonavir. The chromatograms of selectivity studies are shown in Fig. 2. No interfering peaks were observed for the retention time for ombitasvir, paritaprevir and ritonavir in mobile phase blank. The retention times of ombitasvir, paritaprevir and ritonavir in tablet sample and standard drug solutions are same. Thus, proved the selectivity of the method.

Linearity: Linearity was assessed at concentration range 6.25-31.25 $\mu \mathrm{g} / \mathrm{mL}$ for ombitasvir, $37.5-187.5 \mu \mathrm{g} / \mathrm{mL}$ for paritaprevir and $25-125 \mu \mathrm{g} / \mathrm{mL}$ for ritonavir. A good linear relationship was established at these ranges between drug peak area response and drug concentration. Good linearity was proved by high values of correlation coefficient. The results were tabulated in Table- 2 .

TABLE-1

SYSTEM SUITABILITY RESULTS FOR OMBITASVIR, PARITAPREVIR AND RITONAVIR

\begin{tabular}{lccc|cc|cc}
\hline \multirow{2}{*}{ Parameter } & \multirow{2}{*}{\begin{tabular}{c} 
Recommended \\
\cline { 3 - 8 }
\end{tabular}} & limits & \multicolumn{2}{c}{ Ombitasvir } & \multicolumn{2}{c|}{ Paritaprevir } & \multicolumn{2}{c}{ Ritonavir } \\
\hline Peak area & \%SD $\leq 2$ & 18441 & 0.738 & 164513 & 1.220 & 196752 & 1.532 \\
Theoretical plates & $>2000$ & 2673.57 & 1.605 & 3062.75 & 1.813 & 5904.09 & 1.034 \\
Retention time & $\%$ RSD $\leq 2$ & 2.045 & 1.969 & 2.832 & 0.888 & 4.894 & 1.477 \\
Tailing factor & $\leq 2$ & 1.388 & 0.851 & 1.461 & 1.327 & 1.351 & 0.983 \\
\hline
\end{tabular}

*Mean value of six determinations. 

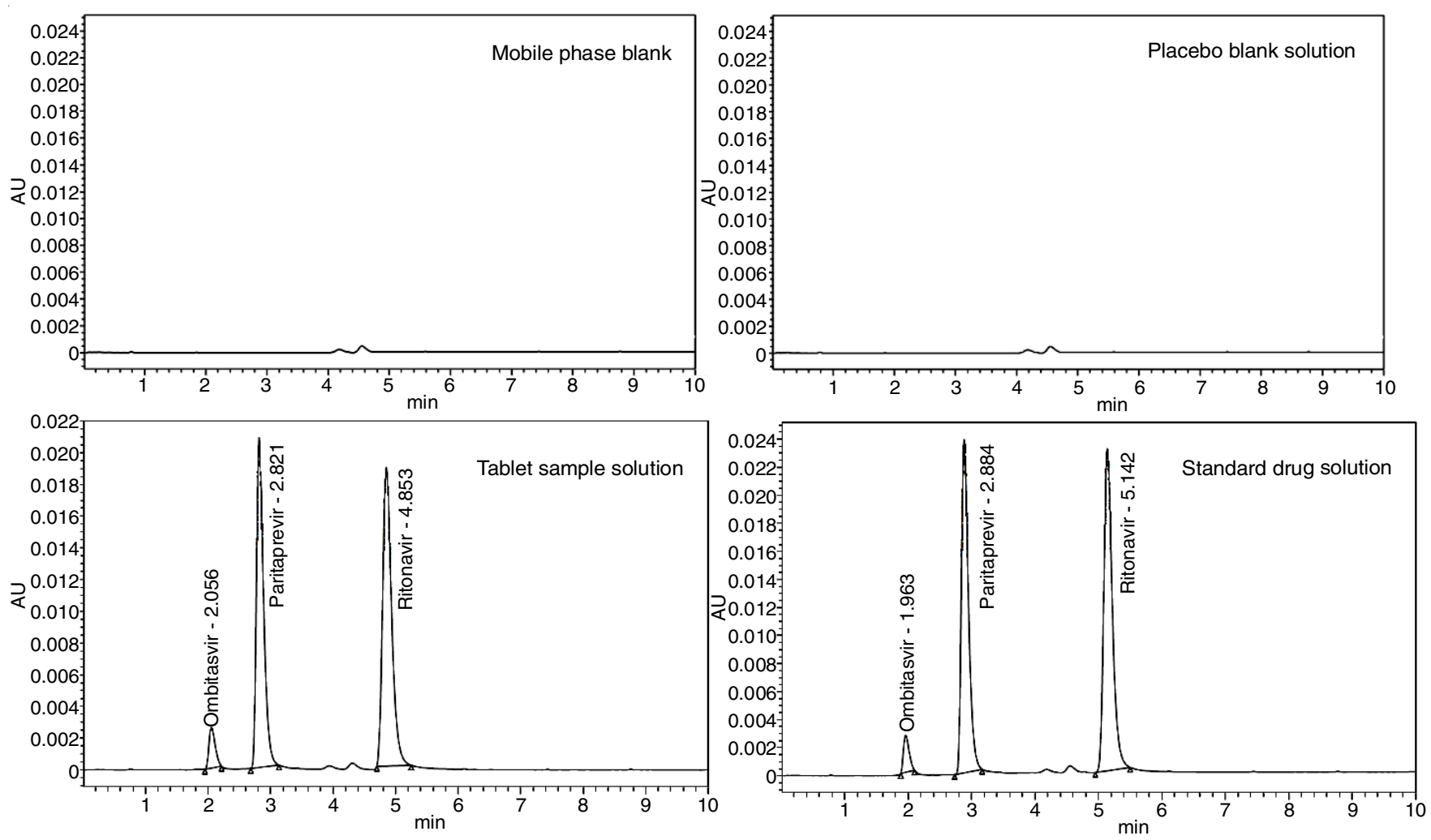

Fig. 2. Chromatograms of mobile phase blank, placebo blank, tablet sample and standard solutions

Limits of detection and quantification: The limit of detection (LOD) and limit of quantification (LOQ) were evaluated by serial dilutions of ombitasvir, paritapravir and ritonavir stock solution to obtain signal to noise ratio of 3:1 for LOD and 10:1 for LOQ. The LOD and LOQ values for ombitasvir, paritapravir and ritonavir are given in Table-2. The low values indicated the adequate sensitivity of the proposed method for the quantification of the studied drugs.
Precision: Six replicate injections of a known concentration (ombitasvir - $25 \mu \mathrm{g} / \mathrm{mL}$, paritaprevir - $150 \mu \mathrm{g} / \mathrm{mL}$ and ritonavir $100 \mu \mathrm{g} / \mathrm{mL}$ ) of tablet sample solution (for method precision) and standard drug solution (for system precision) of ombitasvir, paritaprevir and ritonavir are analyzed on the same day. From the results obtained, the percentage of relative standard deviation for peak area was calculated and was found to be within the limits $(\mathrm{RSD}<2 \%)$. The results of precision are given in Table-3.

TABLE-2

LINEARITY, LOD AND LOQ DATA FOR OMBITASVIR, PARITAPREVIR AND RITONAVIR

\begin{tabular}{lccc}
\hline \multicolumn{1}{c}{ Parameter } & Ombitasvir & Paritaprevir & Ritonavir \\
\hline Linearity $(\mu \mathrm{g} / \mathrm{mL})$ & $6.25-31.25$ & $37.5-187.5$ & $25-125$ \\
Regresstion equation $\left(\mathrm{y}^{\mathrm{a}}=\mathrm{m} \mathrm{x}^{\mathrm{b}}+\mathrm{c}\right)$ & $\mathrm{y}=11237 \mathrm{x}+518.9$ & $\mathrm{y}=3009 \mathrm{x}+160.7$ & $\mathrm{y}=3003 \mathrm{x}+234.2$ \\
Slope $(\mathrm{m})$ & 11237 & 3009 & 3003 \\
Intercept $(\mathrm{c})$ & 518.9 & 160.7 & 234.2 \\
Correlation coefficient $\left(\mathrm{R}^{2}\right)$ & 0.9997 & 0.9996 & 0.9996 \\
LOD $(\mu \mathrm{g} / \mathrm{mL})$ & 2.95 & 2.95 & 2.96 \\
$\mathrm{LOQ}(\mu \mathrm{g} / \mathrm{mL})$ & 9.92 & 9.92 & 9.96 \\
\hline
\end{tabular}

${ }^{\mathrm{a}}$ Peak area; ${ }^{\mathrm{b}}$ Concentration of ombitasvir/paritaprevir/ritonavir in $\mu \mathrm{g} / \mathrm{mL}$

TABLE-3

SYSTEM AND METHOD PRECISION DATA FOR OMBITASVIR, PARITAPREVIR AND RITONAVIR

\begin{tabular}{ccc|cc|cc}
\hline \multirow{2}{*}{ Injection No. } & \multicolumn{2}{c|}{ Ombitasvir } & \multicolumn{2}{c|}{ Paritaprevir } & \multicolumn{2}{c}{ Ritonavir } \\
\cline { 2 - 6 } & System precision & Method precision & System precision & Method precision & System precision & Method precision \\
\hline 1 & 18747 & 18546 & 165948 & 166467 & 200042 & 198084 \\
2 & 18557 & 18751 & 167167 & 167987 & 196141 & 199752 \\
3 & 18734 & 18439 & 165221 & 167204 & 195760 & 199646 \\
4 & 18707 & 18711 & 168078 & 164480 & 195298 & 198872 \\
5 & 18601 & 18678 & 166590 & 165372 & 196457 & 200345 \\
6 & 18963 & 18513 & 165231 & 167321 & 194986 & 197875 \\
Mean & 18718 & 18606 & 166373 & 166472 & 196447 & 199096 \\
RSD (\%) & 0.756 & 0.669 & 0.680 & 0.794 & 0.937 & 0.495 \\
\hline
\end{tabular}


Accuracy: The accuracy of the method was established through recovery experiment. A known amount of the standard drug at three concentrations level (50,100 and $150 \%)$, was added to the preanalyzed tablet sample. Per cent recovery of the spiked drug was determined at each added concentration level. The percentage recovery of ombitasvir, paritaprevir and ritonavir was achieved between 99.98-100.69\%, 99.16-100.75 $\%$ and $99.82-100.08 \%$, respectively. The results are given in Table-4. The good per cent recoveries of ombitasvir, paritaprevir and ritonavir indicated the accuracy of the method and also the non-interference of tablet excipients in the assay of the studied drugs by the proposed method.

\begin{tabular}{|c|c|c|c|}
\hline \multicolumn{4}{|c|}{$\begin{array}{c}\text { TABLE-4 } \\
\text { PERCENT RECOVERY OF OMBITASVIR, } \\
\text { PARITAPREVIR AND RITONAVIR }\end{array}$} \\
\hline \multirow{2}{*}{$\begin{array}{c}\text { Spiked } \\
\text { level }(\%)\end{array}$} & \multicolumn{2}{|c|}{ Amount of drug } & \multirow{2}{*}{$\begin{array}{c}\text { Recovery } \\
(\%)\end{array}$} \\
\hline & Spiked $(\mu \mathrm{g} / \mathrm{mL})$ & Found* $(\mu \mathrm{g} / \mathrm{mL})$ & \\
\hline \multicolumn{4}{|c|}{ Ombitasvir } \\
\hline 50 & 12.5 & 12.5 & 99.98 \\
\hline 100 & 25.0 & 25.17 & 100.69 \\
\hline 150 & 37.5 & 37.60 & 100.25 \\
\hline \multicolumn{4}{|c|}{ Paritaprevir } \\
\hline 50 & 75 & 74.63 & 100.75 \\
\hline 100 & 150 & 148.74 & 99.16 \\
\hline 150 & 225 & 225.41 & 100.18 \\
\hline \multicolumn{4}{|c|}{ Ritonavir } \\
\hline 50 & 50 & 50.01 & 100.03 \\
\hline 100 & 100 & 99.82 & 99.82 \\
\hline 150 & 150 & 150.12 & 100.08 \\
\hline
\end{tabular}

Ruggedness: Method ruggedness was accessed by analyzing standard solution of ombitasvir, paritaprevir and ritonavir six times on the same day and on two consecutive days in two different laboratories by two different analysts. The \% RSD was calculated. Results were found within the acceptance limits $(\mathrm{RSD}<2 \%)$ as shown in the Table-5.

Robustness: The method robustness was confirmed by studying the effect of slight changes on the assay of ombitasvir, paritaprevir and ritonavir by the proposed method. Three parameters were selected to be studied in the robustness: the mobile phase composition and flow rate. Results of system suitability parameters during robustness study are shown in Table-6. It was observed that none of these variables had significant effect system suitability parameters. Hence, the proposed method is considered robust.

Specificity: In order to determine the specificity and stability indicating nature of the proposed method, the studied drugs were exposed to different ICH recommended stress conditions such as acidic, basic, oxidative and thermal degradation conditions. The results of the degradation studies are shown in Table-7. The chromatograms of ombitasvir, paritaprevir and ritonavir in all degradation conditions are shown in Fig. 3. From the percentage of degradation values it was observed that all the studied drugs degraded in all the applied stress conditions. The ritonavir and ombitasvir are less stable in alkaline condition whereas paritaprevir is less stable to oxidation. The ombitasvir, paritaprevir and ritonavir are more stable to neutral stress conditions applied. The proposed RP-HPLC method well analyzed ombitasvir, paritaprevir and ritonavir in the presence of their degradation products. Therefore, the developed method

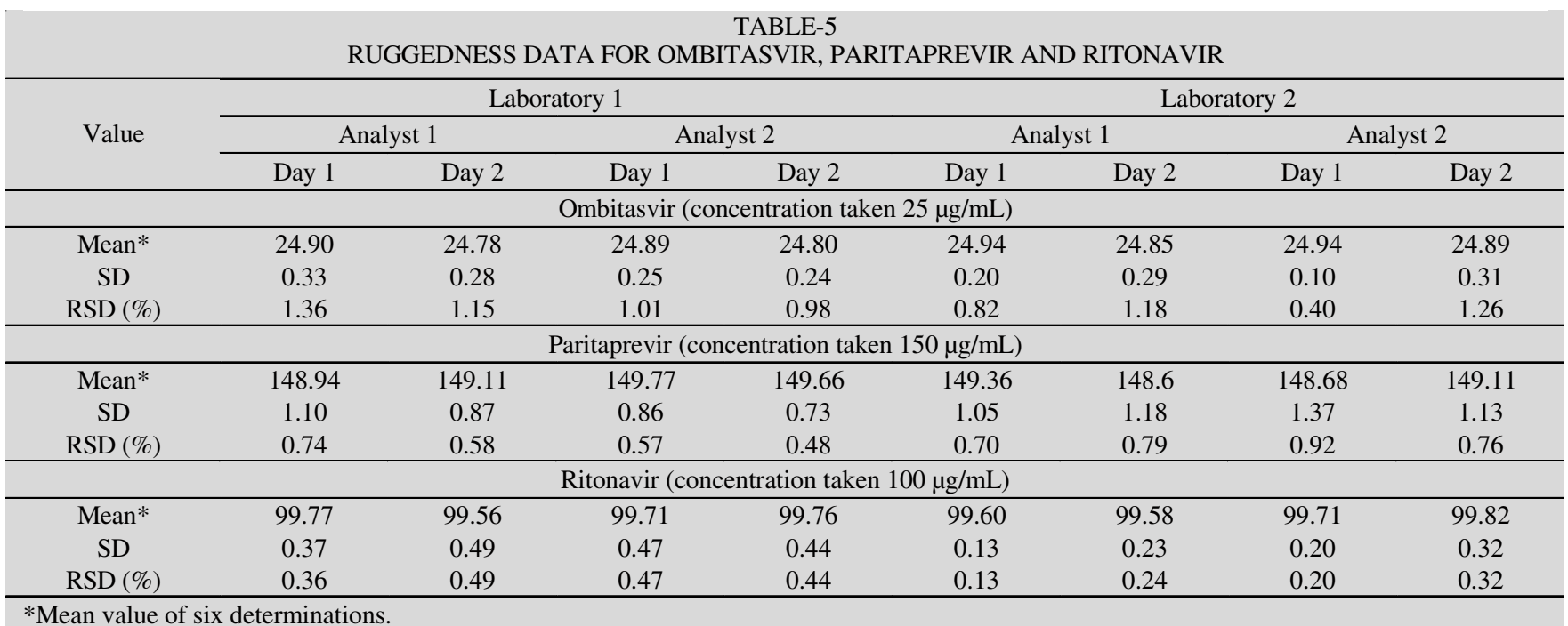

TABLE-6

ROBUSTNESS DATA FOR OMBITASVIR, PARITAPREVIR AND RITONAVIR

\begin{tabular}{cccc|cc|cc}
\hline \multirow{2}{*}{ Parameter } & \multirow{2}{*}{ Value } & \multicolumn{2}{c|}{ Ombitasvir $(25 \mu \mathrm{g} / \mathrm{mL})$} & \multicolumn{2}{c|}{ Paritaprevir $(150 \mu \mathrm{g} / \mathrm{mL})$} & \multicolumn{2}{c}{ Ritonavir $(100 \mu \mathrm{g} / \mathrm{mL})$} \\
\cline { 3 - 8 } & & Plate count & Tailing factor & Plate count & Tailing factor & Plate count & Tailing factor \\
\hline \multirow{2}{*}{ Flow rate } & 0.8 & 2828.94 & 1.42 & 2528.32 & 1.35 & 4312.75 \\
$(\mathrm{~mL} / \mathrm{min})$ & 1.0 & 2768.97 & 1.41 & 2442.26 & 1.34 & 3976.31 & 1.21 \\
& 1.2 & 2773.51 & 1.43 & 2442.59 & 1.35 & 4101.72 & 1.21 \\
\hline \multirow{2}{*}{ Mobile phase } & $35: 65$ & 2796.70 & 1.42 & 2466.2 & 1.34 & 4143.88 & 3976.31 \\
ratio $(\mathrm{v} / \mathrm{v})$ & $40: 60$ & 2768.97 & 1.41 & 2442.26 & 1.34 & 1.20 \\
& $45: 55$ & 2811.61 & 1.43 & 2483.38 & 1.35 & 4196.02 & 1.22 \\
\hline
\end{tabular}



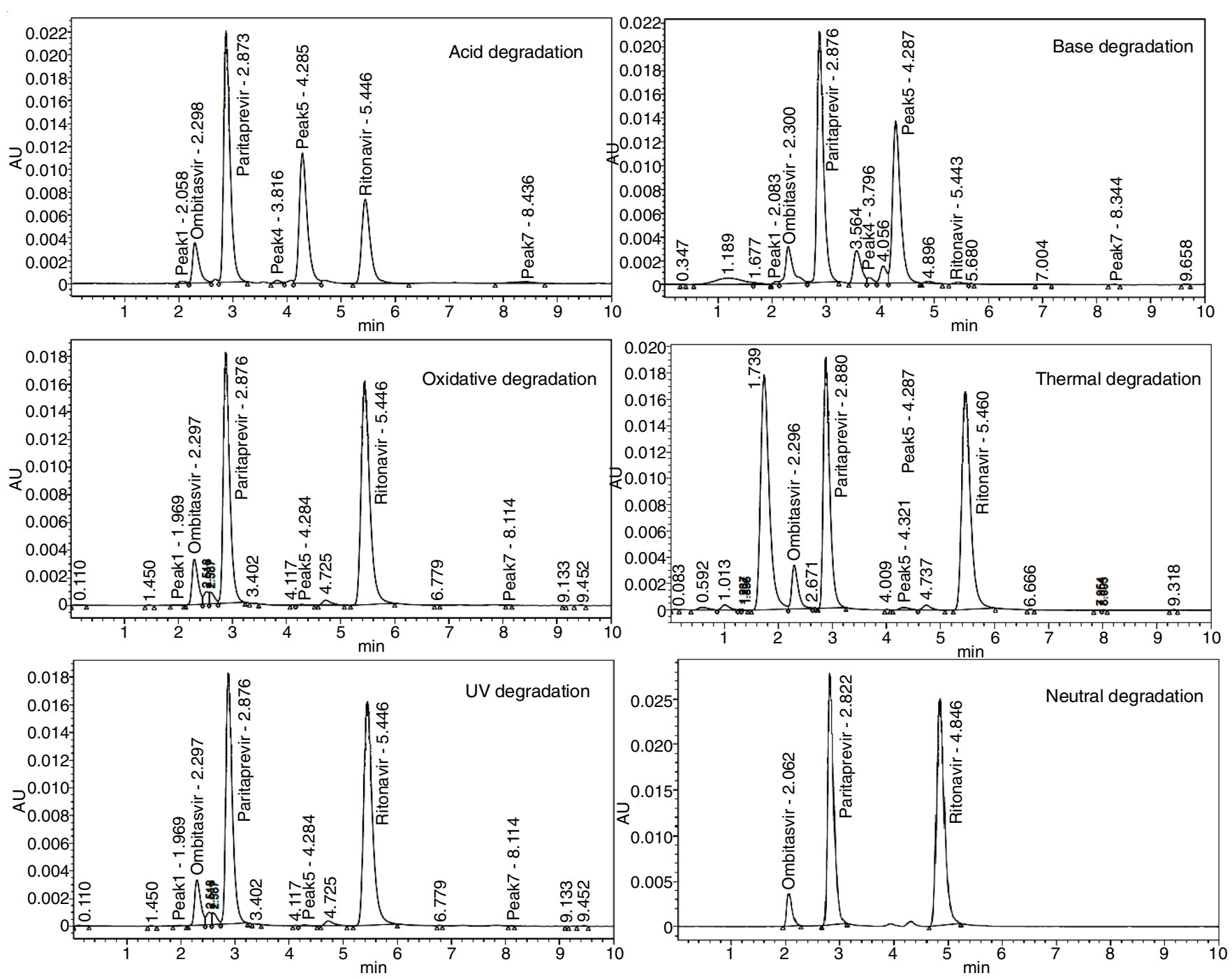

Fig. 3. Chromatograms of ombitasvir, paritaprevir and ritonavir after applying stress degradation conditions

\begin{tabular}{|c|c|c|c|c|}
\hline \multicolumn{5}{|c|}{$\begin{array}{l}\text { TABLE-7 } \\
\text { DEGRADATION DATA FOR OMBITASVIR, } \\
\text { PARITAPREVIR AND RITONAVIR }\end{array}$} \\
\hline Drug & $\begin{array}{l}\text { Type of } \\
\text { stress }\end{array}$ & Peak area & $\begin{array}{c}\text { Recovered } \\
(\%)\end{array}$ & $\begin{array}{c}\text { Degraded } \\
(\%)\end{array}$ \\
\hline \multirow{6}{*}{ 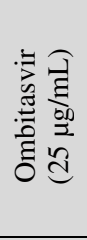 } & Acid & 17423 & 94.48 & 5.52 \\
\hline & Base & 16230 & 88.01 & 11.99 \\
\hline & Peroxide & 17632 & 95.61 & 4.39 \\
\hline & Thermal & 16581 & 89.91 & 10.09 \\
\hline & UV light & 17632 & 95.61 & 4.39 \\
\hline & Water & 17924 & 97.20 & 2.80 \\
\hline \multirow{6}{*}{ 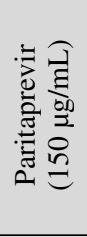 } & Acid & 159430 & 96.92 & 3.08 \\
\hline & Base & 154829 & 94.15 & 5.85 \\
\hline & Peroxide & 148299 & 90.15 & 9.85 \\
\hline & Thermal & 156427 & 95.09 & 4.91 \\
\hline & UV light & 148299 & 90.14 & 9.86 \\
\hline & Water & 159723 & 97.09 & 2.91 \\
\hline \multirow{6}{*}{ 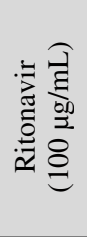 } & Acid & 181612 & 92.31 & 7.69 \\
\hline & Base & 178005 & 90.48 & 9.52 \\
\hline & Peroxide & 178538 & 90.75 & 9.25 \\
\hline & Thermal & 184959 & 94.01 & 5.99 \\
\hline & UV light & 178538 & 90.74 & 9.26 \\
\hline & Water & 190485 & 96.82 & 3.18 \\
\hline
\end{tabular}

is to be considered specific for the assay of ombitasvir, paritaprevir and ritonavir combination and also proven the stability indicating nature.

The described RP-HPLC method was applied to tablet dosage forms to assess the content of studied drug combination. In the present study, a Technivie ${ }^{\mathrm{TM}}$ tablet (labeled to contain ombitasvir $12.5 \mathrm{mg}$, paritaprevir $75 \mathrm{mg}$ and ritonavir $50 \mathrm{mg}$ ) was analyzed. The percentage assay and percent relative standard deviation values are determined (Table-8). The values indicated the accuracy and precision of the developed RPHPLC method for the assay of ombitasvir, paritaprevir and ritonavir combination in tablet dosage forms without interference from the tablet excipients.

\section{Conclusion}

The present paper reports the development and validation for a stability indicating RP-HPLC method with photodiode array detector for the simultaneous estimation of ombitasvir, paritaprevir and ritonavir. The proposed method has acceptable validation characteristics according to International Conference on Harmonization guidelines for the studied drugs. Statistical analysis of the validation parameters did not any 


\begin{tabular}{|c|c|c|c|c|c|c|}
\hline \multirow{3}{*}{ Injection No. } & \multicolumn{5}{|c|}{$\begin{array}{c}\text { TABLE-8 } \\
\text { ASSAY OF OMBITASVIR, PARITAPREVIR AND RITONAVIR IN TABLETS }\end{array}$} & \\
\hline & \multicolumn{6}{|c|}{\begin{tabular}{|l|l|l} 
Ombitasvir & Paritaprevir &
\end{tabular}} \\
\hline & Labeled claim (mg) & Assay (\%) & Labeled claim (mg) & Assay (\%) & Labeled claim (mg) & Assay (\%) \\
\hline 1 & 12.5 & 99.65 & 75 & 99.77 & 50 & 102.21 \\
\hline 2 & 12.5 & 99.45 & 75 & 98.89 & 50 & 97.72 \\
\hline 3 & 12.5 & 100.32 & 75 & 99.15 & 50 & 99.94 \\
\hline 4 & 12.5 & 98.15 & 75 & 102.14 & 50 & 100.18 \\
\hline 5 & 12.5 & 100.72 & 75 & 102.85 & 50 & 99.01 \\
\hline 6 & 12.5 & 98.92 & 75 & 100.52 & 50 & 98.81 \\
\hline Mean & - & 99.54 & - & 100.55 & - & 99.65 \\
\hline RSD & - & 0.935 & - & 1.614 & - & 1.537 \\
\hline
\end{tabular}

significant differences within results. The method was successfully applied to commercially available tablet dosage form with accuracy and precision. Therefore, the method is suitable for the routine simultaneous quantification of ombitasvir, paritaprevir and ritonavir in tablet dosage forms.

\section{REFERENCES}

1. P.S. Badri, D.L. Shuster, S. Dutta and R.M. Menon, Clin. Pharmacokinet., 56, 1103 (2017);

https://doi.org/10.1007/s40262-017-0518-4.

2. J. Shen, M. Serby, B. Surber, A.J. Lee, J. Ma, P. Badri, O. Kavetskaia, R. Menon, S.M. de Morais, J. Sydor and V. Fischer, Drug Metab. Dispos., 44, 1148 (2016); https://doi.org/10.1124/dmd.115.067496.

3. R.M. Menon, A.R. Polepally, A. Khatri, W.M. Awni and S. Dutta, Clin. Pharmacokinet., 56, 1125 (2017); https://doi.org/10.1007/s40262-017-0520-X.

4. R.M. Menon, C.E. Klein, T.J. Podsadecki, Y.-L. Chiu, S. Dutta and W.M. Awni, Br. J. Clin. Pharmacol., 81, 929 (2016);

https://doi.org/10.1111/bcp.12873.
5. M.W. Hull and J.S.G. Montaner, Ann. Med., 43, 375 (2011); https://doi.org/10.3109/07853890.2011.572905.

6. R.K. Zeldin and R.A. Petruschke, J. Antimicrob. Chemother, 53, 4 (2003); https://doi.org/10.1093/jac/dkh029.

7. http://www.centerwatch.com/drug-information/fda-approved-drugs/ drug/100087/technivie-ombitasvir-paritaprevir-and-ritonavir/?mp=.

8. G.M. Keating, Drugs, 76, 1203 (2016); https://doi.org/10.1007/s40265-016-0612-1.

9. B. Srinivas and P. Yadagiriswamy, Int. J. Anal. Bioanal. Chem., 7, 12 (2017).

10. R.S.Ch. Phani, K.R.S. Prasad and U.R. Mallu, Orient. J. Chem., 33, 2363 (2017); https://doi.org/10.13005/ojc/330528.

11. International Conference on the Harmonization, ICH Harmonized Tripartite Guideline. Stability Testing of New Drug Substances and Products Q1A (R2), November (2003).

12. International Conference on the Harmonization, ICH Harmonized Tripartite Guideline. Validation of Analytical Procedures: Text and Methodology Q2 (R1), November (2005). 